\title{
Simulation and Performance Evaluation of Shunt Hybrid Power Filter for Power Quality Improvement Using PQ Theory
}

\author{
R. Balasubramanian ${ }^{1}$, S. Palani ${ }^{2}$ \\ ${ }^{1}$ Department of Electrical and Electronics Engineering, Sastra University, Thanjavur, India \\ ${ }^{2}$ Department of Electronics and Communication Engineering, Sudharsan Engineeering College, Pudukkottai, India
}

\begin{abstract}
Article Info
Article history:

Received May 30, 2016

Revised Aug 16, 2016

Accepted Aug 30, 2016

Keyword:

Harmonics

Hybrid filter

Hysteresis control

Power quality

Total harmonic distortion

ABSTRACT

This work proposes the design of shunt hybrid filter using instantaneous power theory to improve the power quality and simulation has been carried out for 3 phase distribution system feeding different types of non linear loads. The proposed filter consists of parallel combination of $5^{\text {th }}$ and $7^{\text {th }}$ tuned selective harmonic elimination passive filters, which is connected in series with a small rating IGBTs based voltage source inverter. In this work, principle of compensation and filtering behavior of the system has been discussed in detail. Instantaneous real and reactive power theory based controller has been designed to estimate the reference current from the distorted current. In order to reduce the harmonics, generated reference currents are tracked by voltage source inverter using hysteresis band current controller. The performance of the hybrid scheme is evaluated for various nonlinear loads using Matlab/ Simulink tool. The detailed analysis has been carried out on harmonics reduction and DC bus voltage regulation and the simulation result ensures the feasibility of suggested control strategy. The proposed topology improves the filtering performance of the passive filter in hybrid scheme.
\end{abstract}

Copyright (C) 2016 Institute of Advanced Engineering and Science. All rights reserved.

Corresponding Author:

R. Balasubramanian,

Department of Electrical and Electronics Engineering,

SASTRA University,

Tirumalaisamudram, Thanjavur- 613401, India.

Email: rbalu@eee.sastra.edu

\section{INTRODUCTION}

Proliferation of nonlinear loads in a power distribution network causes various power problems related to its quality in the distribution network. Among various power quality problems harmonics play a major role due to its detrimental effects like overheating of electric motors and transformers winding etc [1-2]. Extensive research work has been reported in the literature to mitigate the level of harmonics present in the power network used for distribution. Harmonics present in the distribution system can be eliminated by employing passive filters with the limitations like parallel and series resonance with system impedance [3]. In order to mitigate this problem a power converter based active power filters are preferred for harmonic elimination [4]. Active filters are suffered due to its high dc link voltage requirements and high power (kVA) rating of the switches. The effective compensation of harmonics in high power applications will be achieved by hybrid filter which consists of both passive and active filter.

In hybrid compensation scheme various topologies are presented in the literature for the reduction of harmonics and compensation of reactive power [1], [5]. D. Rivas et al [6] have proposed shunt hybrid filter scheme, which is the combination of active filter connected in series with single tuned passive filter. In this topology active filter aid the compensation performance of the passive filter while the rating of active filter is small. A number of control methods has been suggested for hybrid filter, such as nonlinear and linear control, lyapunov control, adaptive control, control based on fuzzy logic, neural network control etc [7-10]. 
In this paper design and simulation of hybrid active power filter connected in shunt with the three phase distribution system feeding nonlinear load is presented. The designed system mitigates the harmonics and also compensates the reactive power. In hybrid topology, the power rating of the active power filter will be lesser when compared with existing conventional filters by suitably connecting the parallel combination of $5^{\text {th }}$ and $7^{\text {th }}$ tuned circuit in series [11]. Using Instantaneous power control theory [12], reference current waveform is generated to controlling the active part of the filter and the compensating current is injected by proper gating using fixed-band hysteresis current controller. The performance of the control technique is analyzed for the designed controller from the simulated waveforms using Matlab/Simulink tool.

\section{SYSTEM CONFIGURATION}

The Shunt hybrid active power filter topology is depicted in Figure 1. It consists of an active power filter connected in series with $5^{\text {th }}$ and $7^{\text {th }}$ tuned passive filters connected in parallel combination. This topology acquires the benefits of both passive as well as active filters and also provides effective compensation of harmonics with cost effective solutions. The problem of series and parallel resonance present between the system impedance and passive filter can be suppressed inherently by this configuration.

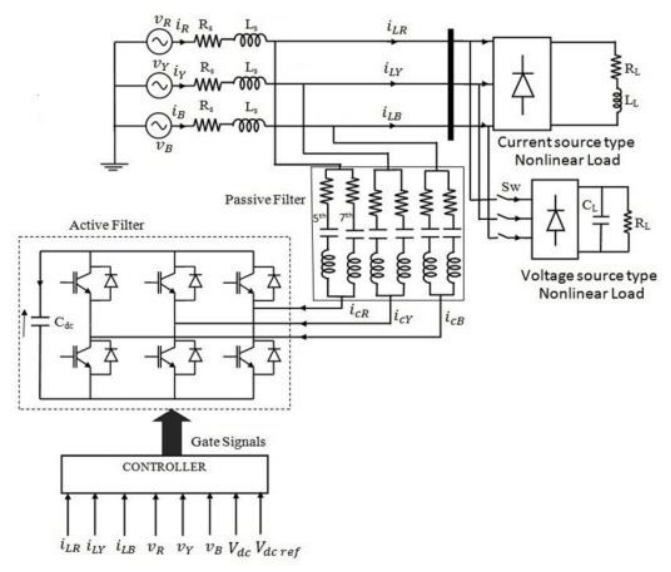

Figure 1. System Configuration

\section{INSTANTANEOUS POWER THEORY}

The p-q theory can applied to draw the reference current signal from the harmonic polluted load current generated by the nonlinear loads. Instantaneous p-q theory is applicable for transient and steady state analysis for both the three wire and four wire distribution system [13]. For a given active power filter, the switching signals of IGBT's is obtained from reference current deduced from distorted load currents.

Instantaneous voltage and current of the three phase distribution system can be obtained by expressing the three phase system quantities mathematically by three instantaneous space vectors. Three phase system currents and voltages are converted in to $\alpha \beta 0$ coordinates by the following equations.

$$
\begin{aligned}
& {\left[\begin{array}{c}
v_{0} \\
v_{\alpha} \\
v_{\beta}
\end{array}\right]=\sqrt{\frac{2}{3}}\left[\begin{array}{ccc}
1 / \sqrt{2} & 1 / \sqrt{2} & 1 / \sqrt{2} \\
1 & -1 / 2 & -1 / 2 \\
0 & \sqrt{3} / 2 & -\sqrt{3} / 2
\end{array}\right]\left[\begin{array}{c}
v_{a} \\
v_{b} \\
v_{c}
\end{array}\right]} \\
& {\left[\begin{array}{l}
i_{0} \\
i_{\alpha} \\
i_{\beta}
\end{array}\right]=\sqrt{\frac{2}{3}}\left[\begin{array}{ccc}
1 / \sqrt{2} & 1 / \sqrt{2} & 1 / \sqrt{2} \\
1 & -1 / 2 & -1 / 2 \\
0 & \sqrt{3} / 2 & -\sqrt{3} / 2
\end{array}\right]\left[\begin{array}{c}
i_{a} \\
i_{b} \\
i_{c}
\end{array}\right]}
\end{aligned}
$$

For balanced three phase three wire system, zero sequence components will be eliminated, hence $v_{0}$ and $i_{0}$ can be neglected from the analysis. Finally using $\alpha$ and $\beta$ coordinates phasors of the instantaneous voltage and currents are defined as follows, 


$$
\begin{aligned}
& v=v_{\alpha}+j v_{\beta} \\
& i=i_{\alpha}+j i_{\beta}
\end{aligned}
$$

The instantaneous complex power is found as,

$$
\begin{aligned}
& s=v i^{*}=\left(v_{\alpha}+v_{\beta}\right)\left(i_{\alpha}-j i_{\beta}\right) \\
& =p+j q
\end{aligned}
$$

where, $\mathrm{p}$ and $\mathrm{q}$ are instantaneous active and instantaneous reactive powers respectively.

$$
\left[\begin{array}{l}
p \\
q
\end{array}\right]=\left[\begin{array}{cc}
v_{\alpha} & v_{\beta} \\
-v_{\beta} & v_{\alpha}
\end{array}\right]\left[\begin{array}{l}
i_{\alpha} \\
i_{\beta}
\end{array}\right]
$$

Further, currents are deduced from the above equation as

$$
\left[\begin{array}{l}
i_{\alpha} \\
i_{\beta}
\end{array}\right]=\frac{1}{v_{\alpha}^{2}+v_{\beta}^{2}}\left[\begin{array}{cc}
v_{\alpha} & -v_{\beta} \\
v_{\beta} & v_{\alpha}
\end{array}\right]\left[\begin{array}{l}
p \\
q
\end{array}\right]
$$

\section{PROPOSED CONTROL METHOD}

The control method for the harmonic reduction of distribution system using shunt hybrid compensator can be achieved by the following three stages.

Stage 1 Stage 2

The reference current waveforms are generated by sensing the load current and filter current.

Stage 3

In second stage, compensation current reference is extracted by pq theory [14].

The gating signals of the voltage source inverter are generated using hysteresis current controller for effective compensation.

The compensator must be designed properly to eliminate the oscillating components in the load. For the compensation of reactive power the dc bus voltage of the link capacitor must be maintained constant. The active and reactive powers obtained from equation (4) can be divided in to steady and oscillating components as explained below.

$$
\left[\begin{array}{l}
p \\
q
\end{array}\right]=\left[\begin{array}{l}
\bar{p}+\tilde{p} \\
\bar{q}+\tilde{q}
\end{array}\right]
$$

where,

$\bar{p}$ and $\bar{q}$ are the average active and reactive powers

$\tilde{p}$ and $\tilde{q}$ are the active and reactive powers of oscillating component.

Separation of oscillating components can be achieved by low pass filters. If the filter is designed for reactive power compensation and harmonic reduction, it is essential to eliminate the oscillating components of real and reactive powers along with average component of reactive power. The reference current in $\alpha \beta$ coordinate is required to obtain necessary compensation and it has been be calculated from the equation (5) as shown below.

$$
\left[\begin{array}{ll}
i_{\alpha} \text { ref } \\
i_{\beta \text { ref }}
\end{array}\right]=\frac{1}{v_{\alpha}^{2}+v_{\beta}^{2}}\left[\begin{array}{cc}
v_{\alpha} & -v_{\beta} \\
v_{\beta} & v_{\alpha}
\end{array}\right]\left[\begin{array}{c}
\tilde{p} \\
\bar{q}+\tilde{q}
\end{array}\right]
$$

The reference current in abc coordinate for switching signal generation can be found from the above equation as follows

IJECE Vol. 6, No. 6, December $2016: 2603$ - 2609 


$$
\left[\begin{array}{l}
i_{\text {a.ref }} \\
i_{\text {b.ref }} \\
i_{c . r e f}
\end{array}\right]=\sqrt{\frac{2}{3}}\left[\begin{array}{cc}
1 & 0 \\
\frac{-1}{2} & \frac{\sqrt{3}}{2} \\
\frac{-1}{2} & \frac{-\sqrt{3}}{2}
\end{array}\right]\left[\begin{array}{c}
i_{\alpha . r e f} \\
i_{\beta . r e f}
\end{array}\right]
$$

\subsection{Hysteresis Current Control}

The reference current is obtained from the distorted current and the error signal is obtained by comparing the reference current with measured filter current. The error signal is used to generate the gating signal for voltage source inverter using hysteresis current controller [15-16]. Hysteresis controller is implemented with two level comparators where, switching commands are issued when the error signals exceeds a tolerance band ' $\pm \mathrm{h}$ '. The proposed control scheme with hysteresis controller is shown in Figure 2.

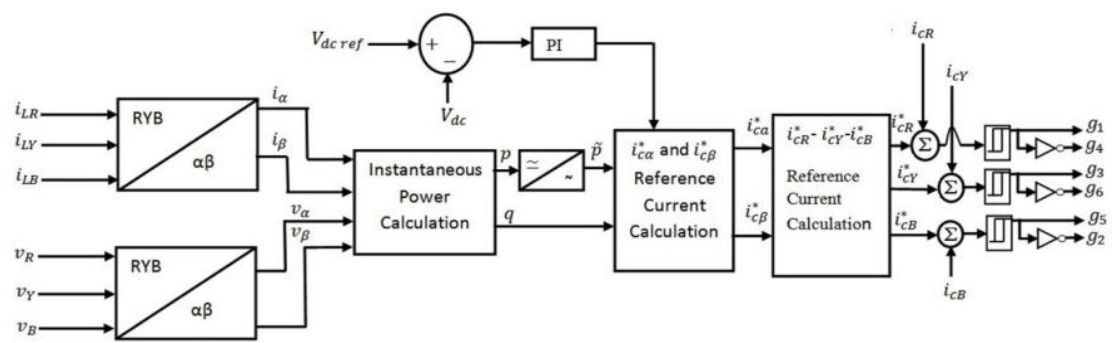

Figure 2. Schematic of Control Circuit

\subsection{Link Voltage Control}

In hybrid compensation technique active power flow in to the voltage source inverter of the hybrid scheme is to be controlled for maintaining dc link voltage as constant. DC bus voltage regulation is more important in order to enhance the filtering performance of the designed filter. Switching losses of the active power filter must be made equal to the active power flow into the hybrid filter for maintaining the dc-link voltage as constant. A PI regulator is designed to keep the dc bus voltage equal to the reference voltage $\mathrm{V}_{\mathrm{dc}}{ }^{*}$.

\section{SIMULINK MODEL OF HYBRID COMPENSATOR}

Simulink model of shunt hybrid power filter along with the power distribution system is depicted in Figure 3. The nonlinear loads are modeled as three phase full bridge rectifier supplying RL and RC type of loads and connected to the three phase ac mains. The shunt hybrid power filter composed of parallel combination of $5^{\text {th }}$ and $7^{\text {th }}$ tuned selective harmonics elimination passive filters connected in series with IGBTs based active power filter terminated with de link capacitor. Simulation of the power distribution system with the proposed controller is carried out using ode45 (Dormand-prince) solver.

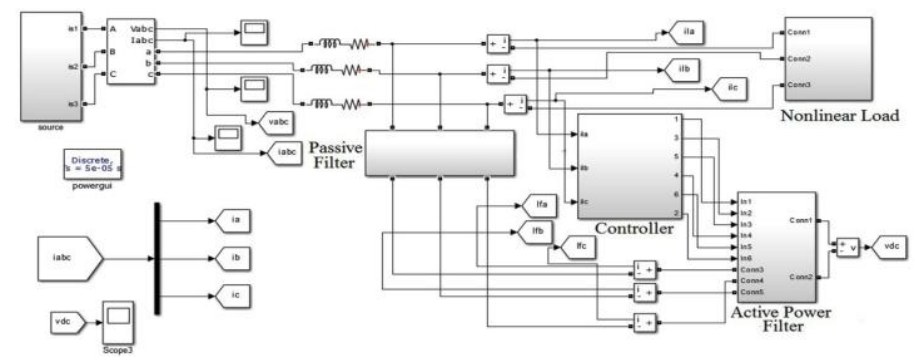

Figure 3. Simulink schematic of the hybrid power filter and controller 


\section{SIMULATION RESULTS}

The simulation of power distribution system with the proposed control strategy has been implemented using power system block set of Matlab/ Simulink software. Here, by considering various types of nonlinear loads as given below, the performance of the designed compensator is evaluated:

1) Current source type nonlinear load

2) Voltage source type nonlinear load

The parameters of the power system are given in Table 1 .

Table 1. Specification of Parameters

\begin{tabular}{ll}
\hline Phase voltage and Frequency & $\mathrm{V}_{\mathrm{srms}}=230 \mathrm{~V}$ and $\mathrm{f}_{\mathrm{s}}=50 \mathrm{~Hz}$ \\
\hline Line Impedance & $\mathrm{R}_{\mathrm{s}}=0.1 \Omega, \mathrm{L}_{\mathrm{s}}=4 \mathrm{mH}$ \\
Load & Full bridge Diode rectifier \\
Load Resistance & $26 \mathrm{ohm}$ \\
Load Inductance & $10 \mathrm{mH}$ \\
Load capacitance & $1000 \mu \mathrm{F}$ \\
DC-link voltage of compensator and Capacitance & $\mathrm{V}_{\mathrm{dc}}=50 \mathrm{~V}, \mathrm{C}_{\mathrm{dc}}=6600 \mu \mathrm{F}$ \\
\hline
\end{tabular}

Case (i) Three phase rectifier feeding RL load

Three phase mains supplies a full bridge diode rectifier feeding RL load causes harmonic distortion in the supply current. The proposed compensator is connected at the point of common coupling as depicted in Figure 1 with the parameter values as given in the Table 1 to carry out the simulation. The results shown in Figure 4(a)-(e) shows the waveforms of source voltage, load current, source current, compensator current and dc link voltage respectively. Figure 5 gives the harmonic spectrum of the supply current before and after compensation. The results show that the Total Harmonic Distortion (THD) of the source current is reduced from $22.17 \%$ to $3.42 \%$ also the supply current waveforms are nearly sinusoidal due to the introduction of hybrid power filter.

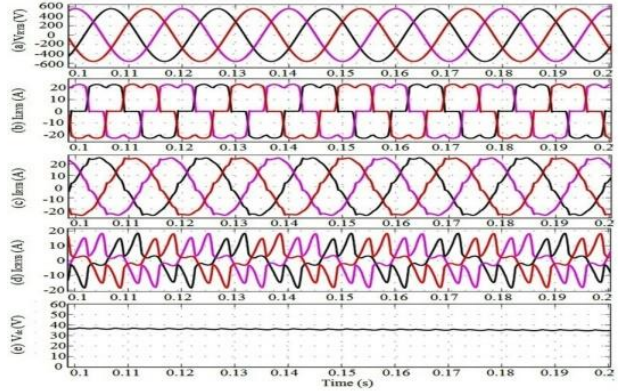

Figure 4. Response of the Filter for a Current Source Type Nonlinear Load
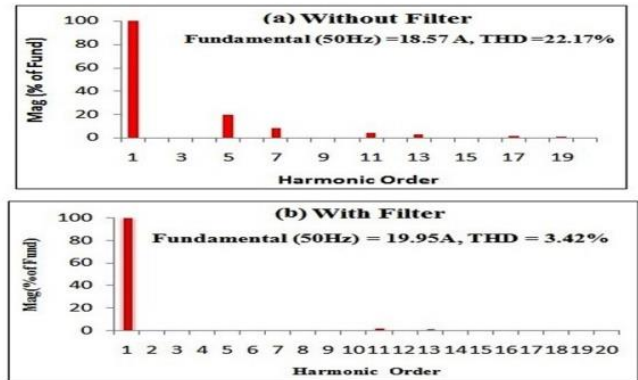

Figure 5. Harmonic Spectrum of Supply Current

Case (ii) Three phase rectifier feeding RC load

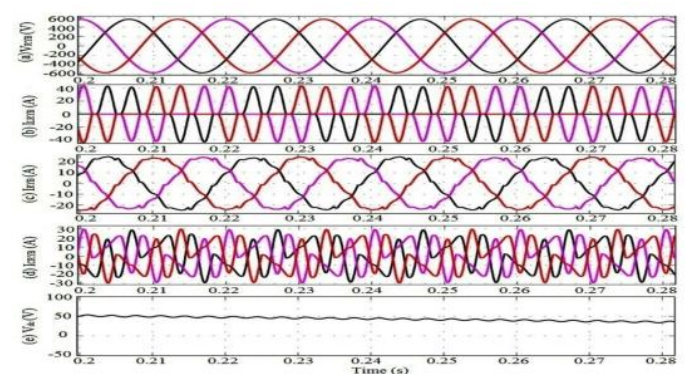

Figure 6. Filter Performance for a Voltage Source Type Nonlinear Load 
The simulation has been carried out by considering voltage source type nonlinear load and the controller performances are obtained. The source voltage, load current, supply current, filter current and dc link capacitor voltages are shown in Figure 6(a)-(e). The FFT of supply current before and after compensation is depicted in Figure 7. Simulation results clearly show that the THD of the supply current is reduced from $27.31 \%$ to $4.15 \%$. The supply current waveform is nearly sinusoidal and the dc link capacitor voltage is also maintained constant.
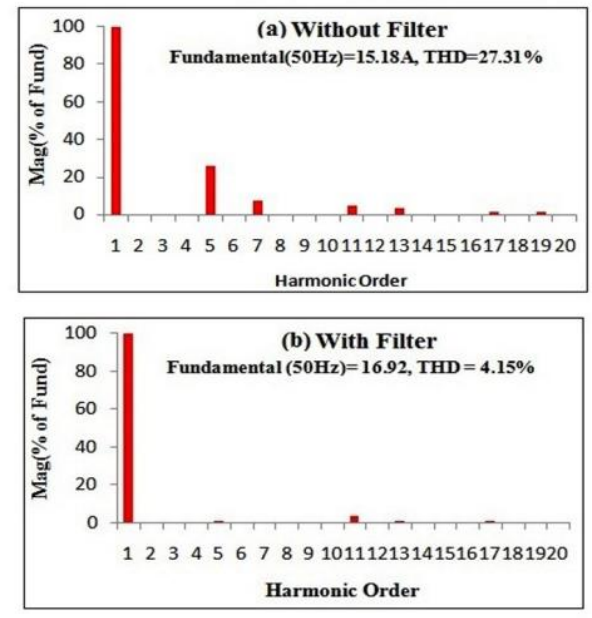

Figure 7. Supply current FFT spectrums

\section{CONCLUSION}

In this work a shunt hybrid compensator using pq theory based control technique is suggested for harmonics mitigation and reactive power compensation in a distribution system feeding nonlinear loads. The performance of the designed compensator with the suggested control strategy is analyzed for voltage and current source type nonlinear loads. The combination of $5^{\text {th }}$ and $7^{\text {th }}$ tuned filter strengthens the performance of the hybrid scheme in high power applications. The simulation results show that the THD caused by voltage source type nonlinear load has been reduced from $22.17 \%$ to $3.42 \%$ and for current source type loads THD has been reduced from $27.31 \%$ to $4.15 \%$. The supply current waveforms are nearly sinusoidal in both the cases due to the presence of proposed filter. The dc link capacitor voltage is maintained constant during the operation of the filter ensures the reactive power compensation aechieved by the proposed filter. The hysteresis control is a very simplest control method and also gives fast dynamic response. DC link bus voltage of the proposed topology has been maintained to the reference value under different types of loading conditions.

\section{REFERENCES}

[1] B. Singh, et al., "Hybrid filters for power quality improvement", IEE Proc.-Gener. Transm. Distrib, vol.152, pp. 365-378, May 2005.

[2] M. Jawad Ghorbani and H. Mokhtari, "Impact of Harmonics on Power Quality and Losses in Power Distribution Systems", International Journal of Electrical and Computer Engineering, Vol. 5, pp. 166-174, February 2015.

[3] J.C. Das, "Passive Filters-Potentialities and Limitations", IEEE Transactions on Industry Applications, vol.40, pp. 232-241, January/Febrary 2004.

[4] Deepthi Janyavula and Dr. Satyendra Nath Saxena, "Unbalanced Variable Nonlinear Load Compensation Using Multiple Shunt Active Filters”, International Journal of Electrical and Computer Engineering, Vol. 5, pp. 896-904, October 2015.

[5] An Luo et al., "Combined System for Harmonic Suppression and Reactive Power Compensation", IEEE Transactions on Industrial Electronics, vol. 56, pp. 418-428, February 2009.

[6] Darwin Rivas et al., "Improving Passive Filter Compensation Performance with Active Techniques", IEEE Transactions on Industrial Electronics, vol. 50, pp. 161-170, February 2003.

[7] Salem Rahmani et al., "A New Control Technique for Three-Phase Shunt Hybrid Power Filter", IEEE Transactions on Industrial Electronics, vol. 56, pp. 2904-2915, August 2009.

[8] Salem Rahmani et al., "A Lyapunov-Function-Based Control for a Three-Phase Shunt Hybrid Active Filter", IEEE Transactions on Industrial Electronics, vol. 59, pp. 1418-1429, March 2012. 
[9] Suresh Mikkili and A K Panda, "Real-time implementation of PI and fuzzy logic controllers based shunt active filter control strategies for power quality improvement", International Journal of Electrical Power and Energy Systems, vol. 43, pp 1114-1126, 2012.

[10] Tejas Zaveri, et al., "Comparison of control strategies for DSTATCOM in three-phase, four-wire distribution system for power quality improvement under various source voltage and load conditions", International journal of Electrical power and energy systems, vol 43, pp 582-594, 2012.

[11] Subhashish Bhattacharya, et al., "Hybrid Solutions for Improving Passive Filter Performance in High Power Applications", IEEE Transactions on Industry Applications, vol. 33, pp. may/june 1997.

[12] C.S.Lam, et al., "Hysteresis current control of hybrid active power filters", IET Power Electronics, vol. 5, pp. 1175-1187, 2012.

[13] Akagi H, et al., "Instantaneous power theory and application to power conditioning", Wiley/IEEE Press, 2007.

[14] L. Merabet, et al., "A comparative study of harmonic currents extraction by simulation and implementation", International journal of Electrical power and energy systems, vol.53, pp 507-514, 2013.

[15] Y. Kusuma Latha, et al., "Control Strategy for Three Phase Shunt Active Power Filter with Minimum Current Measurements", International Journal of Electrical and Computer Engineering, Vol.1, pp. 31- 42, September 2011.

[16] Anup Kumar Panda and Suresh Mikkili, "FLC based shunt active filter (p-q and Id-Iq) control strategies for mitigation of harmonics with different fuzzy MFs using MATLAB and real-time digital simulator", International Journal of Electrical Power and Energy Systems, vol. 47, pp. 313-336, 2013.

\section{BIOGRAPHIES OF AUTHORS}

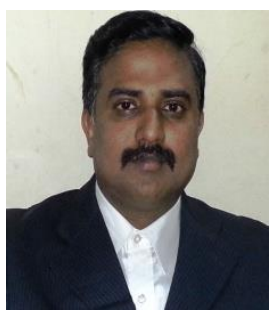

R. Balasubramanian was born in Thennamanadu, Thanjavur, India, in 1977 . He received the B.E degree in electrical and electronics engineering from the University of Madras, India, in 1999 and the M.Tech degree in control systems and Instrumentation from SASTRA University, Thanjavur, India in 2006. He is currently pursuing his Ph.D Degree in SASTRA University. Presently he is working as an Assistant Professor at the Department of Electrical and Electronics Engineering, School of Electrical and Electronics Engineering SASTRA University. His research interests include Power quality improvements, control systems and Power electronics.

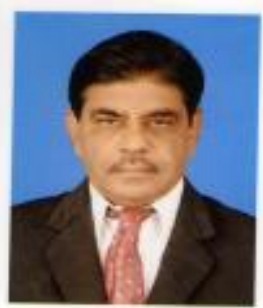

S. Palani received B.E degree in electrical engineering from the University of Madras, India, in 1966, the M.Tech degree in control systems engineering from IIT, Kharagpur, India in 1968, and $\mathrm{Ph} . \mathrm{D}$ in control systems engineering from University of Madras, India in 1982 with academic excellence. He has wide teaching experience over four decades.He started his teaching career in the year 1968 at Regional engineering college (now National Institute of Technology) Tiruchirappalli in the department of EEE and occupied various positions. He is currently with the department of Electronics and Communication Engineering, Sudharsan Engineering College, Pudukkottai, India, as a Dean and Professor. He has authored many books related to control systems engineering. His area of research interest includes design of intelligent controllers for dynamic systems, Digital Signal Processing and Image Processing. 